\title{
Chemical deposition of silica-based thin films under supercritical carbon dioxide atmosphere using tetraethylorthosilicate precursor with oxidizing agents
}

\author{
Hiroshi UCHIDA, ${ }^{\dagger}$ Katsushi IZAKI and Marina SHIOKAWA \\ Department of Materials and Life Sciences, Sophia University, Tokyo 102-8554, Japan
}

\begin{abstract}
Supercritical fluid deposition (SCFD) of $\mathrm{SiO}_{2}$-based films was proposed using TEOS precursor with oxidizing agents, for the purpose of low-temperature film deposition. The film deposition was performed in a batch-type closed chamber filled with supercritical carbon dioxide $\left(\mathrm{CO}_{2}\right)$ fluid. The $\mathrm{SiO}_{2}$-based films were deposited on aluminum electrodes coated on silicon wafers (Al/Si) at the substrate temperature above $150^{\circ} \mathrm{C}$. Oxidizing agents such as $\mathrm{O}_{2}$ gas and aqueous $\mathrm{H}_{2} \mathrm{O}_{2}$ solution promoted the removal of $\mathrm{C}_{2} \mathrm{H}_{5} \mathrm{OH}$ byproduct and the formation of strong $\mathrm{Si}-\mathrm{O}$ network, whereas it also promoted the homogeneous nucleation of granular precipitation and the $\mathrm{H}_{2} \mathrm{O}$ adsorption in/on the resulting films. The processing temperature of the SCFD was significantly lower than those by thermal CVD and comparable or higher than those by plasma-enhanced CVD, although the resulting films obtained exhibited relatively large dielectric loss which depends on the presence of $\mathrm{C}_{2} \mathrm{H}_{5} \mathrm{OH}$ and $\mathrm{H}_{2} \mathrm{O}$ byproducts. @2016 The Ceramic Society of Japan. All rights reserved.
\end{abstract}

Key-words : Thin film, Silicon dioxide, Chemical deposition, Supercritical fluid, Carbon dioxide, Dielectrics

[Received August 31, 2015; Accepted October 22, 2015]

\section{Introduction}

Film-deposition process is recognized as one of core technology for fabricating integrated circuits assembled in various electronic devices such as versatile LSIs, semiconductive memories (flash, DRAM, FeRAM, RRAM, etc.), advanced silicon-based MEMS devices, etc. Current processes of the film deposition mainly consist of so-called "build-up" steps, i.e., precursor transfer via diffusion of gaseous or liquid species onto the substrate surface, followed by construction of the objective material with the form of solid thin film. ${ }^{1)}$ This route can be applied to the deposition of ceramic thin films with a variety of chemical compositions (e.g., metal oxides, nitrides, carbides, etc.), as well as those of metal, organic molecular and polymer films. Major examples of the ceramic materials include simple oxides (such as $\mathrm{SiO}_{2}, \mathrm{Al}_{2} \mathrm{O}_{3}, \mathrm{ZrO}_{2}, \mathrm{HfO}_{2}, \mathrm{CeO}_{2}, \mathrm{RuO}_{2}$, etc.) to complex oxides $\left(\mathrm{SrTiO}_{3}, \mathrm{In}_{2} \mathrm{O}_{3}-\mathrm{SnO}_{2}, \mathrm{SrRuO}_{3}\right.$, etc.) that exhibit unique functionalities (properties of dielectric/ferroelectric, electric, optic, etc.) as versatile components in electronic devices.

Various kinds of techniques have been developed for depositing ceramic thin films, mainly those with metal-oxide compositions: Typically, physical vapor deposition (PVD) techniques, such as sputtering and pulsed-laser deposition, chemical vapor deposition (CVD) including atomic layer deposition, and chemical solution deposition (CSD), are adopted by many researchers and manufacturers as conventional techniques. Almost all the fabrication systems for existing electronic devices are basically organized by the combination of these processes, because each technique includes its characteristic feature for the resulting films, which depends on its film-deposition mechanism; e.g., gas diffusion of CVD resources would be suitable for conformal deposition, and, easy handling of CSD precursors would be helpful for

Corresponding author: H. Uchida; E-mail: uchidah@ @ophia.ac.jp

* Preface for this article: Dol http://dx.doi.org/10.2109/jcersj2.124.P1-1 treating multicomponent resources, etc. These techniques follow the basic concept of "build-up" steps, of course, in order to adapt ultra-large-scale integration. However, almost all the techniques still include one unavoidable problem that the processes usually require thermal heating of the deposition system (=substrate surface) for activating chemical reaction or solid-phase diffusion to form the thin film of objective material; Especially note that the deposition for metal-oxide ceramics requires substrate heating at higher temperature rather than those for metal or organic thin films, typically above $400^{\circ} \mathrm{C}$. This problem shall be improved from the viewpoint for avoiding thermal damage on electronic circuits consisting of silicon- and metal-based materials, which will also be of great help for constructing energy-conservation system.

On prospective concept for solving the problem is material processing with external energy support for lowering the process temperature, e.g., via plasma, light (UV/laser), microwave, etc. Here, many researchers including our group have proposed a unique technique, supercritical fluid deposition (SCFD), for depositing thin-film materials in supercritical carbon dioxide $\left(\mathrm{CO}_{2}\right)$ fluid. $^{2)-4)}$ Supercritical fluids are generally recognized as a state of substances that appears in the temperature-pressure range above critical point, where the constituent molecules form highdensity molecular fluid with low viscousity and high diffusivity. They are frequently utilized as functional solvents for material synthesis because of their unique properties of solubility and diffusivity. Then the SCFD includes the transportation of a organometallic precursor and its deposition on the substrate, which is fully accomplished in supercritical $\mathrm{CO}_{2}$. Supercritical " $\mathrm{CO}_{2}$ " fluid is selected as the reaction field of SCFD because of its favorable characteristics, e.g., its excellent solubility of various organometallic species, high diffusivity comparable to gaseous molecules, and relatively moderate critical temperature and pressure $\left(T_{\mathrm{c}}=31.1^{\circ} \mathrm{C}\right.$ and $\left.P_{\mathrm{c}}=7.38 \mathrm{MPa}\right)$ compared with other supercritical fluids $\left(\mathrm{H}_{2} \mathrm{O}\right.$, etc.). Preceding researches 
clarified the unique features of the SCFD, e.g., diverse routes for synthesis of multi-component materials using various types of organometallic precursors, ${ }^{2), 5)-7)}$ and conformal film deposition (comparable to CVD process) on small features with complicated geometry such as trenches and contact holes with sizes of submicrons. ${ }^{8)-10)}$ Also, the SCFD exhibited some favorable properties for low-temperature deposition, ${ }^{11)-13)}$ that would be related to its deposition route based on dissolution/re-precipitation mechanism ${ }^{14)}$ and byproduct removal via supercritical extraction through surrounding $\mathrm{CO}_{2}$ fluid. ${ }^{15)}$

The preceding researches for SCFD are mainly focused on the fabrication of metal films, such as $\mathrm{Cu}, \mathrm{Ni}, \mathrm{Ru}, \mathrm{Pt}$, to form highquality metal electrodes applicable for integrated circuits (ICs) in various electronic devices. ${ }^{16)-18)}$ On the other hand, the SCFD focused on the fabrication of metal-oxide thin films have also been reported in recent researches, that provide some favorable results for constructing fundamental components in integrated circuits. 5),6),19),20) Our group have reported some technical achievements by SCFD of $\mathrm{TiO}_{2}, \mathrm{HfO}_{2}$ and $\mathrm{ZrO}_{2}$ thin films, that discussed their features for low-temperature film deposition as well as con-

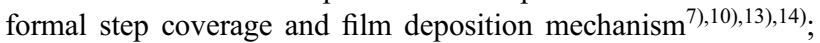
film deposition was examined by the SCFD below $300^{\circ} \mathrm{C}$ in our reports. These results suggest that the SCFD can be a prospective candidate for fabricating a wide variety of metal-oxide components in/on the integrated circuits for various electronic devices.

Here, we report the SCFD experiment for depositing silica $\left(\mathrm{SiO}_{2}\right)$-based thin films, which is frequently utilized as insulating layers and dielectric capacitors in ICs. The experiment aims for low-temperature material deposition by SCFD, mainly compared with conventional CVD processes. The material synthesis was designed using a typical alkoxide precursor, tetraethylorthosilicate (TEOS), which is an environmental-friendly compound compared with other organometallic compounds of Si. Also, effects of oxidizing agents were examined for lowering the process temperature of SCFD, with expectation of promoted reactions of TEOS decomposition and $\mathrm{SiO}_{2}$ formation. For the brief model case of low-temperature deposition, the films were deposited on aluminum (Al) electrodes, which have relatively lower thermal stability than other metals, and then were evaluated as dielectric capacitors.

\section{Experimental}

SCFD of the $\mathrm{SiO}_{2}$ film was accomplished using a batchtype closed reaction system. A schematic diagram of the film deposition apparatus is illustrated in Fig. 1. The reaction system consisted of a closed stainless steel vessel (inner volume: $9 \mathrm{~cm}^{3}$ ) with a substrate heater, a $\mathrm{CO}_{2}$ delivery system and a gas-exhaust system, which is connected with stainless steel tubes $(\phi=$ $1 / 8$ inch). Liquefied $\mathrm{CO}_{2}$ (Taiyo Nippon Sanso, $>99.9 \%$ ) was utilized as a source of supercritical $\mathrm{CO}_{2}$ fluid. Tetraehylorthosilicate $\left[\mathrm{Si}\left(\mathrm{OC}_{2} \mathrm{H}_{5}\right)_{4}\right.$, TEOS, Wako pure chemical industry, special grade] was selected as a precursor compound; preceding works have clarified the relatively high solubility of TEOS in supercritical $\mathrm{CO}_{2}$ fluid. ${ }^{20), 21)}$ Oxygen gas $\left(\mathrm{O}_{2}\right)$ and hydrogen peroxide aqueous solution $\left(\mathrm{H}_{2} \mathrm{O}_{2}\right.$, Wako pure chemical industry, $30 \%$ ) were utilized as oxidizing agents for assisting $\mathrm{SiO}_{2}$ formation from TEOS precursor. Firstly, TEOS and a silicon $(\mathrm{Si})$ substrate coated with $\mathrm{Al}$ electrode $\left(\mathrm{Al} / \mathrm{Si}\right.$, size: $10 \times 10 \times 0.2 \mathrm{~mm}^{3}$, electrode thickness: $\sim 100 \mathrm{~nm}$ ) were encapsulated in the stainless steel vessel, together with an oxidizing agent as necessary. The loading amounts of TEOS precursor and oxidizing agents were controlled to be equivalent to the concentrations of $7.2 \times 10^{-2}$ and $1.4 \times 10^{-2} \mathrm{~mol} / \mathrm{dm}^{3}$, respectively, in the closed vessel; these

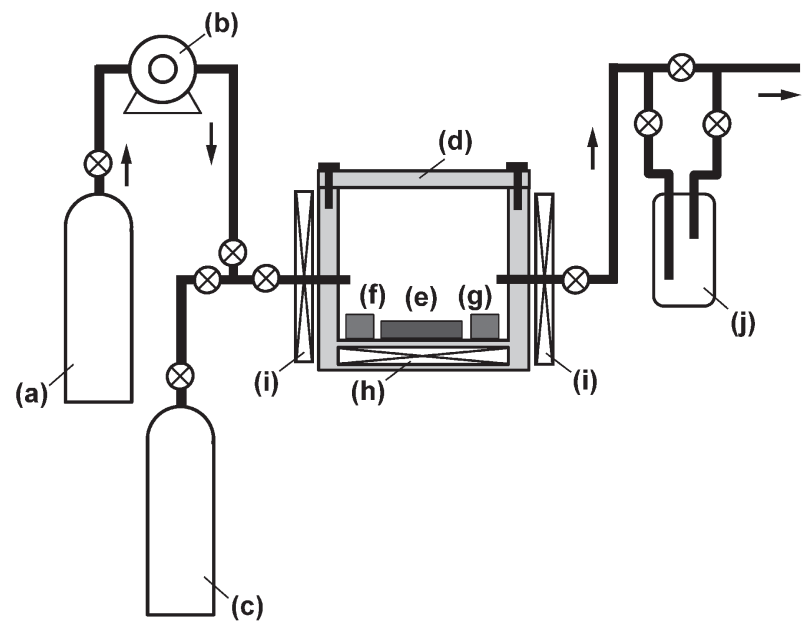

Fig. 1. Schematic diagram of batch-type SCFD apparatus; (a) $\mathrm{CO}_{2}$ cylinder, (b) $\mathrm{CO}_{2}$ delivery pump, (c) $\mathrm{O}_{2}$ cylinder, (d) stainless-steel reaction vessel, (e) substrate, (f) TEOS precursor, (g) oxidizing agent, (h) substrate heater, (i) supporting heater and (j) exhaust trap for collecting residual precursor and byproducts.

conditions were determined by preliminary experiments (data not shown here). Then liquefied $\mathrm{CO}_{2}$ fluid was delivered in the vessel via inlet stainless-steel connection using a liquid-delivery pump. After closing the inlet and outlet connections, the the substrate was heated up to the deposition temperature $\left(100-300^{\circ} \mathrm{C}\right)$ for proceeding the reaction of film deposition under supercritical $\mathrm{CO}_{2}$ atmosphere, and then was kept for $3 \mathrm{~h}$ at the fluid pressure of $15 \mathrm{MPa}$. Finally, the system was cooled down to room temperature, followed by purging $\mathrm{CO}_{2}$ fluid with residual precursor and byproducts via outlet tube connection.

Thickness and microstructure of the resulting films were observed by a scanning electron microscope (SEM, SU-8000, Hitachi). States of interatomic bonding in the films were analyzed using an X-ray photoelectron spectroscope (XPS, PHI 5000 Versa Pro, Ulvac-Phi). Functional groups in the films, mainly derived from residual precursor or byproducts, were identified using an Fourier transform infrared spectrometry (FTIR, Spectrum 2000, Perkin Elmer). The FTIR measurement was conducted by reflection mode where bottom $\mathrm{Al}$ electrode was utilized as a reflection mirror. The dielectric properties (relative dielectric constant and loss factor) of the resulting films were evaluated using an impedance analyzer (4294A, Agilent). The dielectric evaluation was executed on the $\mathrm{SiO}_{2}$ films with circular gold $(\mathrm{Au})$ top electrodes fabricated by vacuum evaporation.

\section{Results and discussion}

\subsection{Deposition characteristic against temperature}

Visual observation confirmed that transparent solid films were formed on $\mathrm{Al} / \mathrm{Si}$ substrates after the SCFD experiments for $3 \mathrm{~h}$ without oxidizing agent at the substrate temperature above $150^{\circ} \mathrm{C}$ whereas viscous liquid-like precipitation without solid deposition were remained after the SCFD below $100^{\circ} \mathrm{C}$. Figure 2 shows representative cross-sectional SEM images of the $\mathrm{Al} / \mathrm{Si}$ substrates after the SCFD at the substrate temperature of (a) $100^{\circ} \mathrm{C}$ and (b) $300^{\circ} \mathrm{C}$, where the viscous precipitation was washed away by rinsing in ethanol before SEM observation. Planar thin film with smooth and flat structure was deposited on the $\mathrm{Al} / \mathrm{Si}$ substrate after SCFD at $300^{\circ} \mathrm{C}$, whereas no solid deposition was found on the $\mathrm{Al} / \mathrm{Si}$ substrate after SCFD at $100^{\circ} \mathrm{C}$ similarly to the results of visual observation. XRD analysis indicated that the 

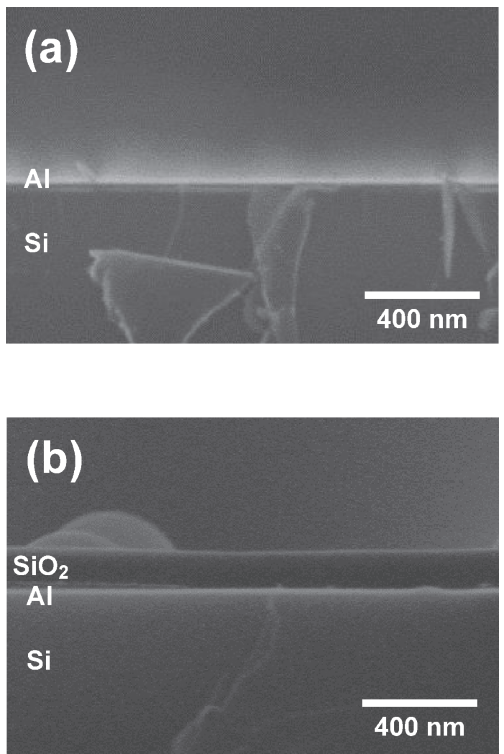

Fig. 2. Cross-sectional SEM images of the Al/Si substrates after SCFD without oxidizing agent. Substrate temperature: (a) $150^{\circ} \mathrm{C}$ and (b) $300^{\circ} \mathrm{C}$.

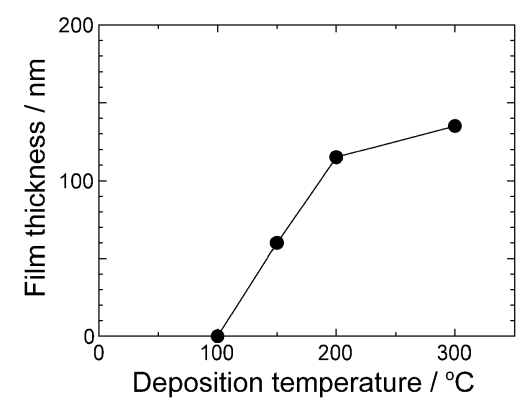

Fig. 3. Relationship between thickness of the resulting film on $\mathrm{Al} / \mathrm{Si}$ substrate and deposition temperature of SCFD without oxidizing agent.

deposited film on $\mathrm{Al} / \mathrm{Si}$ substrate included no crystalline phase. No exfoliation, cracking or abnormal grain growth was arisen on both of the deposited film and the Al electrode layer.

As we know well, the chemical reaction for generating metaloxide materials from TEOS precursor are explained by the following two equations, i.e., hydrolysis of alkoxide group and subsequent polycondensation of silanol group;

$$
\begin{aligned}
& \succ \mathrm{Si}-\mathrm{OC}_{2} \mathrm{H}_{5}+\mathrm{H}_{2} \mathrm{O} \rightarrow \succ_{>} \mathrm{Si}-\mathrm{OH}+\mathrm{C}_{2} \mathrm{H}_{5} \mathrm{OH} \\
& 2 \succ \mathrm{Si}-\mathrm{OH} \rightarrow \succ \mathrm{Si}-\mathrm{O}-\mathrm{Si} i \stackrel{-}{\lessgtr}+\mathrm{H}_{2} \mathrm{O}
\end{aligned}
$$

TEOS molecules with catalytic $\mathrm{H}_{2} \mathrm{O}$ form $\mathrm{Si}-\mathrm{O}-\mathrm{Si}$ network via these reactions together with ethanol $\left(\mathrm{C}_{2} \mathrm{H}_{5} \mathrm{OH}\right)$ byproduct. The authors assume that the material synthesis via SCFD also follows the above route of reaction, ${ }^{22}$ although no catalytic $\mathrm{H}_{2} \mathrm{O}$ was added in this experiment; unavoidable existence of the adventitious $\mathrm{H}_{2} \mathrm{O}$ in the supplied $\mathrm{CO}_{2}$ or in TEOS can act as the catalyst and then promote the reaction of hydrolysis. ${ }^{10)}$

Relationship between thickness of the film and the substrate temperature was plotted in Fig. 3. These results indicate that the film deposition initiates at the temperature range above $150^{\circ} \mathrm{C}$ and that the film thickness increased with with increasing the substrate temperature, at least up to $300^{\circ} \mathrm{C}$. The initial temperature of film deposition by the present SCFD experiment was significantly lower than those by thermal CVD using TEOS precursor (approximately above $450{ }^{\circ} \mathrm{C}^{23), 24)}$ ) and, however,
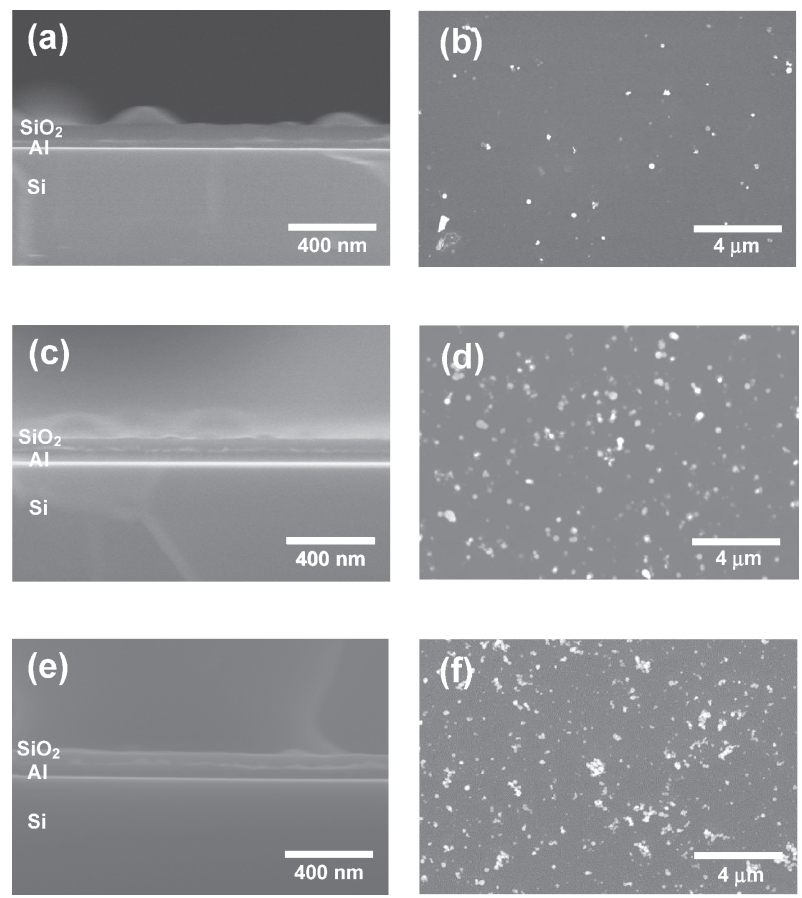

Fig. 4. Cross-sectional [(a), (c) and (e)] and surface [(b), (d) and (f)] $\mathrm{SEM}$ images of the $\mathrm{Al} / \mathrm{Si}$ substrates after SCFD at substrate temperature of $200^{\circ} \mathrm{C}$. Oxidizing agent: (a) (b) no addition, (c) (d) $\mathrm{O}_{2}$ and (e) (f) $\mathrm{H}_{2} \mathrm{O}_{2}$.

relatively comparable or higher than those by plasma-enhanced CVD (approximately $40-200^{\circ} \mathrm{C}^{25), 26)}$ ). The film thickness increased linearly with increasing the deposition time at least up to $3 \mathrm{~h}$. Also, we confirmed that the SCFD experiment using a half amount TEOS precursor yielded almost the same results in Fig. 2, meaning that the loading amount of the precursor is significantly excessive and the reaction of film deposition can proceed under the condition of surface-reaction rate-controlling. Apparent activation energy was roughly estimated to be 30 $\mathrm{kJ} / \mathrm{mol}$, which is and comparable with other SCFD experiments for metal $\left(\mathrm{Cu}^{27)}\right)$ and metal-oxide $\left(\mathrm{TiO}_{2}{ }^{28)}\right)$ deposition.

\subsection{Effect of oxidizing agents}

Subsequently, the SCFD experiments with oxidizing agents were executed for promoting the decomposition of TEOS precursor. Figure 4 shows cross-sectional and surface SEM images of the resulting films on the $\mathrm{Al} / \mathrm{Si}$ substrates fabricated by SCFD with oxidizing agents, together with no addition, at the substrate temperature of $200^{\circ} \mathrm{C}$. The film deposition on $\mathrm{Al}$ electrode with thickness of approximately $100 \mathrm{~nm}$ was found for all of these samples, irrespective of the presence of oxidizing agent; no significant difference was confirmed for the film thickness. However, granular precipitates were formed on the films deposited with oxidizing agents whereas it decreased on the film deposition without oxidizing agent. In the present SCFD system, the oxidizing agents can promote the reaction of homogeneous nucleating to form granular precipitates from TEOS dissolved in supercritical $\mathrm{CO}_{2}$ fluid rather than the heterogeneous film deposition on the substrate surface. XRD analysis clarified that no crystalline phase was presented in these films, implying the deposition of amorphous materials.

Figure 5 shows XPS spectra measured on the surface of the films derived from SCFD at $200^{\circ} \mathrm{C}$ with oxidizing agents, as well as no addition. The film surface mainly consisted of $\mathrm{Si}, \mathrm{O}$ and $\mathrm{C}$ 


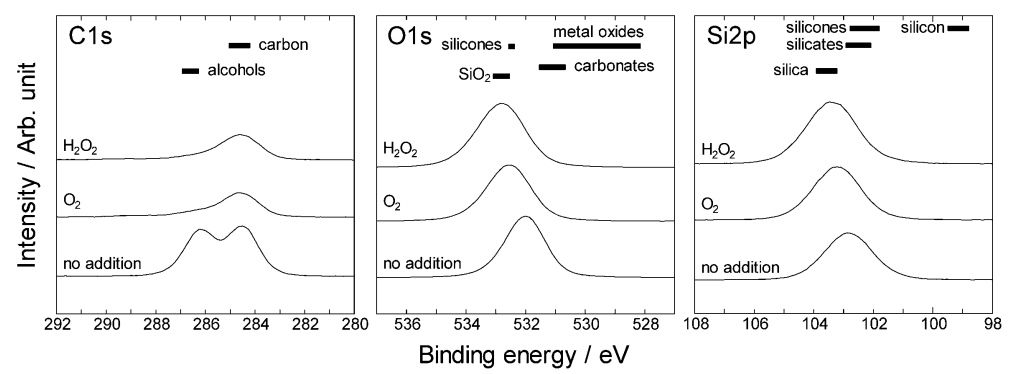

Fig. 5. $\mathrm{C}(1 \mathrm{~s}), \mathrm{O}(1 \mathrm{~s})$ and $\mathrm{Si}(2 \mathrm{p})$ XPS spectra of the resulting films fabricated with $\mathrm{H}_{2} \mathrm{O}_{2}, \mathrm{O}_{2}$ and no addition. Substrate temperature: $200^{\circ} \mathrm{C}$.

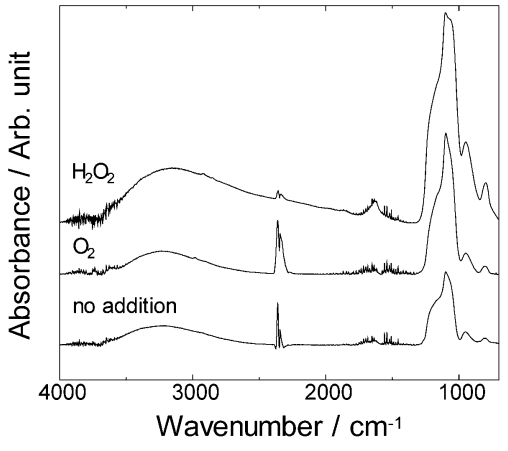

Fig. 6. FTIR spectra of the resulting films on $\mathrm{Al} / \mathrm{Si}$ substrates fabricated with $\mathrm{H}_{2} \mathrm{O}_{2}, \mathrm{O}_{2}$ and no addition. Substrate temperature: $200^{\circ} \mathrm{C}$.

elements. From the $\mathrm{O}(1 \mathrm{~s})$ and $\mathrm{Si}(2 \mathrm{p})$ spectra (peaks around 104 and $533 \mathrm{eV}$ ), we can estimate that these films mainly consisted of any kind of compounds with $\mathrm{Si}-\mathrm{O}$ bonding, such as $\mathrm{SiO}_{2}$ and related compounds with insufficient development of $\mathrm{Si}-\mathrm{O}$ network. The $\mathrm{C}(1 \mathrm{~s})$ spectra suggest that the the film fabricated with no addition includes carbon atoms derived from alcoholic compounds such as TEOS and $\mathrm{C}_{2} \mathrm{H}_{5} \mathrm{OH}$ (XPS peaks around 287 $\mathrm{eV}$ ), whereas it disappeared in the films with $\mathrm{O}_{2}$ or $\mathrm{H}_{2} \mathrm{O}_{2}$. The spectra also indicated the presence of carbon atoms with $\mathrm{C}-\mathrm{C}$ bonding (XPS peaks around $285 \mathrm{eV}$ ) in all the films. They are generally derived from so-called negligible "adventitious carbon" owing to the external adsorption of hydrocarbon species on the film surface. ${ }^{29), 30)}$ The peak positions of $\mathrm{Si}(2 \mathrm{p})$ and $\mathrm{O}(1 \mathrm{~s})$ spectra were shifted slightly to higher binding energy by addition of oxidizing agents, meaning stronger $\mathrm{Si}-\mathrm{O}$ chemical bonding.

FTIR spectra of these films were shown in Fig. 6. All the films exhibited absorbance peaks around $1000-1200 \mathrm{~cm}^{-1}$, derived from presence of $\mathrm{Si}-\mathrm{O}$ network [longitudinal-optic (LO) mode: $\sim 1200 \mathrm{~cm}^{-1}$, cyclic $\mathrm{Si}-\mathrm{O}: \sim 1140 \mathrm{~cm}^{-1}$, transverse-optic (TO) mode: $\sim 1070 \mathrm{~cm}^{-1}{ }^{31)-33)}$ The peak intensity for the films fabricated with oxidizing agents were relatively stronger than that with no addition, which suggests that the $\mathrm{Si}-\mathrm{O}$ network was developed widely by adding oxidizing agents. Also, broad absorbance peak around $2500-3700 \mathrm{~cm}^{-1}$, derived from the presence of $-\mathrm{OH}$ group, ${ }^{34), 35)}$ was enhanced by adding oxidizing agents. It can be caused by $\mathrm{H}_{2} \mathrm{O}$ adsorption or hydration in/on the deposited films during the SCFD process.

From the spectroscopic analyses in Figs. 5 and 6, we confirmed that the addition of oxidizing agents promoted the following phenomena;

(a) Removing alcoholic compounds from the deposited films

(b) Enhancing Si-O chemical bond

(c) Developing $\mathrm{Si}-\mathrm{O}$ network

(d) Increasing $\mathrm{H}_{2} \mathrm{O}$ adsorption or hydration.

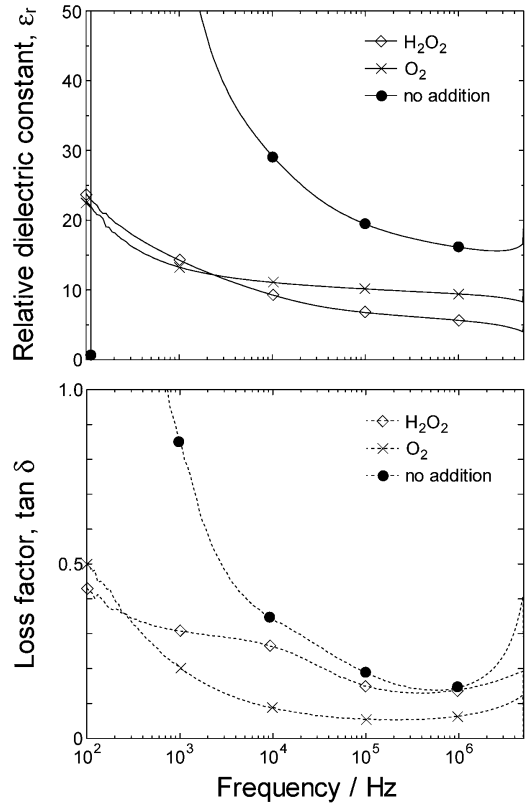

Fig. 7. $\varepsilon_{\mathrm{r}}-F$ curves measured on the $\mathrm{Si}-\mathrm{O}$-based films on $\mathrm{Al} / \mathrm{Si}$ substrates fabricated by SCFD with $\mathrm{H}_{2} \mathrm{O}_{2}, \mathrm{O}_{2}$ and no addition. Substrate temperature: $200^{\circ} \mathrm{C}$.

These results can be explained by simple assumption that oxidizing agents remove the $\mathrm{C}_{2} \mathrm{H}_{5} \mathrm{OH}$ byproduct to form acetic acid $\left(\mathrm{CH}_{3} \mathrm{COOH}\right)$ which acts as a acid catalyst for hydrolysis reaction of the TEOS precursor. It also promotes the development of $\mathrm{Si}-\mathrm{O}$ network with stronger chemical bonding subsequently via polycondensation of silanol groups. However, oxidizing agents can also oxidize $\mathrm{C}_{2} \mathrm{H}_{5} \mathrm{OH}$ or $\mathrm{CH}_{3} \mathrm{COOH}$ byproducts to form $\mathrm{H}_{2} \mathrm{O}$, that will be a origin of $\mathrm{H}_{2} \mathrm{O}$ adsorption or hydration. Furthermore, we note that addition of $\mathrm{H}_{2} \mathrm{O}_{2}$ agent certainly involves aqueous solvent that delivers excessive $\mathrm{H}_{2} \mathrm{O}$ in the SCFD system. We can summarize that oxidizing agents promote the formation of strong $\mathrm{Si}-\mathrm{O}$ network in the SCFD system although it also promotes $\mathrm{H}_{2} \mathrm{O}$ adsorption. The resulting films by SCFD with oxidizing agents would consisted of amorphous $\mathrm{SiO}_{2}$ with $\mathrm{H}_{2} \mathrm{O}$ adsorption, while the film with no addition consisted of amorphous $\mathrm{SiO}_{2}$ together with adsorbed $\mathrm{H}_{2} \mathrm{O}$, residual TEOS precursor and $\mathrm{C}_{2} \mathrm{H}_{5} \mathrm{OH}$ byproduct.

Dielectric evaluation was performed on the $\mathrm{Si}-\mathrm{O}$-based films fabricated by the SCFD at $200^{\circ} \mathrm{C}$. Note that the bottom Al electrodes maintained their electrical conductivity after exposure in supercritical $\mathrm{CO}_{2}$ condition during SCFD, without loss of the conductivity due to the oxidization. Figure 7 shows relative dielectric permittivity, $\varepsilon_{\mathrm{r}}$, and dielectric loss, $\tan \delta$, of the $\mathrm{Si}-\mathrm{O}-$ 
based films fabricated with oxidizing agents as well as no addition. The $\varepsilon_{\mathrm{r}}$ values of the these films were significantly larger than typical $\varepsilon_{\mathrm{r}}$ value for $\mathrm{SiO}_{2}\left(\varepsilon_{\mathrm{r}}=4\right)$, due to apparent capacitance derived from large dielectric loss. The film fabricated with no addition exhibited relatively higher $\tan \delta$, especially at lower frequency range below $10^{4} \mathrm{~Hz}$, meaning the degraded dielectric property due to excessive dielectric loss. However, addition of the oxidizing agents depressed $\tan \delta$ value, meaning the improved dielectric property with lowered dielectric loss. In the present case, residual $\mathrm{C}_{2} \mathrm{H}_{5} \mathrm{OH}$ and $\mathrm{H}_{2} \mathrm{O}$ molecules which can exhibit dielectric relaxation owing to dipole polarization will contribute to larger dielectric losses and their dependence on oscillating frequency. The films fabricated with $\mathrm{O}_{2}$ addition exhibited the lowest $\tan \delta$ value, due to smaller contents of residual $\mathrm{C}_{2} \mathrm{H}_{5} \mathrm{OH}$ and $\mathrm{H}_{2} \mathrm{O}$ as confirmed by XPS and FTIR analyses. Further improvement for the insulating ability (e.g., lowered $\tan \delta$ less than $1 \%$, at least) is required for insulating layers in electronic application. It can be accomplished by any thermal or chemical treatments after SCFD, ${ }^{7}$ for removing adsorbed $\mathrm{H}_{2} \mathrm{O}$.

\section{Conclusions}

Supercritical fluid deposition (SCFD) of $\mathrm{SiO}_{2}$-based films from TEOS precursor with oxidizing agents was proposed for the purpose of low-temperature film deposition. The SCFD experiments were executed using a closed batch-type SCFD system. The film deposition initiated at the substrate temperature above $150^{\circ} \mathrm{C}$, which was significantly lower than those by thermal CVD and comparable or higher than those by plasma-enhanced CVD. Addition of oxidizing agents promoted the removal of $\mathrm{C}_{2} \mathrm{H}_{5} \mathrm{OH}$ byproduct and the formation of $\mathrm{Si}-\mathrm{O}$ network successfully, although it also promoted the homogeneous nucleation to form granular precipitation and the $\mathrm{H}_{2} \mathrm{O}$ adsorption or hydration on/in the resulting films. The resulting films by SCFD exhibited degraded dielectric property with large dielectric loss, however, which can be lowered by removing residual $\mathrm{C}_{2} \mathrm{H}_{5} \mathrm{OH}$ and $\mathrm{H}_{2} \mathrm{O}$ species.

Acknowledgment This research was supported supported by JSPS KAKENHI Grant Number 24760602.

\section{References}

1) R. Waser, "Nanoelectronics and Information Technology", 1st ed.,Wiley VCH, Weinheim (2003) Chap. 8.

2) A. H. Romang and J. J. Watkins, Chem. Rev., 110, 459-478 (2010).

3) E. Reverchon and R. Adami, J. Supercrit. Fluids, 37, 1-22 (2006).

4) X. Ye and M. Wai, J. Chem. Educ., 80, 198-204 (2003).

5) T. Gougousi, D. Barua, E. D. Young and G. N. Parsons, Chem. Mater, 17, 5093-5100 (2005).

6) A. O'Neil and J. J. Watkins, Chem. Mater, 19, 5460-5466 (2007).

7) M. Shiokawa, K. Izaki, H. Funakubo and H. Uchida, Mater. Res. Soc. Symp. Proc., 1729, 99-104 (2015).
8) E. Kondoh and J. Fukuda, J. Supercrit. Fluids, 44, 466-474 (2008).

9) K. Jung, Y. Zhao, T. Momose and Y. Shimogaki, ECS Sol. Stat. Lett., 2, P79-P81 (2013).

10) F. Kano, H. Uchida and S. Koda, J. Supercrit. Fluids, 50, 313319 (2009).

11) D. Barua, T. Gougousi, E. D. Young and G. N. Parsons, Appl. Phys. Lett., 88, 092904 (2006).

12) Q. Wei, E. You, N. R. Hendricks, A. L. Briseno and J. J. Watkins, ACS Appl. Mater. Interfaces, 4, 2322-2324 (2012).

13) H. Uchida, A. Otsubo, K. Itatani and S. Koda, Jpn. J. Appl. Phys., 44, 1901-1906 (2005).

14) H. Uchida, K. Sekino, Y. Hayakawa and S. Koda, J. Supercrit. Fluids, 66, 59-65 (2012).

15) H. Uchida, K. Fujioka and S. Koda, Mater. Res. Soc. Symp. Proc., 1113, F06-27-1-6 (2009).

16) J. M. Blackburn, D. P. Long, A. Cabanas and J. J. Watkins, Science, 294, 141-145 (2001).

17) E. Kondoh, Jpn. J. Appl. Phys., 43, 3928-3933 (2004).

18) T. Momose, M. Sugiyama, E. Kondoh and Y. Shimogaki, Appl. Phys. Express, 1, 097002 (2008).

19) T. Momose, H. Yamada, K. Kitamura, Y. Hattori, Y. Shimogaki and M. Sugiyama, Proceedings of IEEE the 24th International Conference on Micro Electro Mechanical Systems (2011) pp. 1309-1311.

20) J. Wang, Y. Xia, W. Wang, R. Mokaya and M. Poliakoff, Chem. Commun. (Camb.), 210-212 (2005).

21) T. A. Hoefling, D. A. Newnam, R. M. Enick and E. J. Beckman, J. Supercrit. Fluids, 6, 165-171 (1993).

22) D. A. Loy, E. M. Russick, S. A. Yamanaka, B. M. Baugher and K. J. Shea, Chem. Mater, 9, 2264-2268 (1997).

23) F. S. Becker, D. Pawlik, H. Anzinger and A. Spitzer, J. Vac. Sci. Technol., B, 5, 1555-1563 (1987).

24) M. C. Öztürk, J. J. Wortman, Y.-L. Zhong, Z.-W. Ren, R. M. Miller, F. S. Johnson, D. T. Grider and D. A. Abercrombie, Mater. Res. Soc. Sym. Proc., 146, 109-114 (1989).

25) W. J. Patrick, G. C. Schwartz, J. D. Coapple-Sokol, R. Carruthers and K. Olsen, J. Electrochem. Soc., 139, 26042613 (1992).

26) S. C. Deshmukh and E. S. Aydil, Appl. Phys. Lett., 65, 31853187 (1994).

27) M. Matsubara, M. Hirose, K. Tamai, Y. Shimogaki and E. Kondoh, J. Electrochem. Soc., 156, H443-H447 (2009).

28) Y. Zhao, K. Jung, T. Momose and Y. Shimogaki, Thin Solid Films, 553, 184-197 (2014).

29) T. L. Barr and S. Seal, J. Vac. Sci. Technol., A, 13, 1239-1246 (1995).

30) P. Swift, Surf. Interface Anal., 4, 47-51 (1982).

31) R. M. Almedia, Phys. Rev. B, 45, 161-170 (1992).

32) N. Primeau, C. Vautey and M. Langlet, Thin Solid Films, 310, 47-56 (1997).

33) J. Gallardo, A. Duran, D. Di Martino and R. M. Almeida, J. Non-Cryst. Solids, 298, 219-225 (2002).

34) A. Fidalgo and L. M. Ilharco, J. Non-Cryst. Solids, 283, 144 154 (2001).

35) H.-J. Jeon, S.-C. Yi and S. G. Oh, Biomaterials, 24, 4921-4928 (2003). 